\title{
Assessing Creativity in the Classroom
}

\author{
Baptiste Barbot ${ }^{*}$, , Maud Besançon ${ }^{2}$ and Todd I. Lubart ${ }^{2}$ \\ ${ }^{1}$ Yale University, Child Study Center, New Haven, CT, USA \\ ${ }^{2}$ Paris Descartes University, Laboratoire Adaptation Travail Individu (LATI), Paris, France
}

\begin{abstract}
This article provides a historical presentation of creativity assessment from a psychological perspective (since Guilford), from traditional divergent thinking tasks, to current theoretical models of creativity assessment which allow creativity to be assessed in different domains, capturing the multidimensionality of creative potential (e.g. EPoC). These techniques and alternative assessment tools are contextualized by addressing their interest for educational programs which take into account children's needs (as suggested by their creative profile). Finally, we discuss the importance of assessing creativity reliably in the classroom, to study the efficiency of these educational intervention programs aiming to promote student creativity.
\end{abstract}

Keywords: Creativity assessment, divergent thinking, creative style, evaluation of potential for creativity, EPoC.

\section{INTRODUCTION}

"What is creativity?", "Is this student creative?", "How can we improve creativity in children?" These questions are of interest in many fields of social sciences and are regularly addressed by psychologists, educators and teachers. The responses to these questions depend, however, on the general issue of assessing creativity. In our contemporary society in which individuals have to adjust constantly to new problems and find original solutions, creativity is indeed a feature that has become increasingly important. A crucial issue for both creativity research and practical applications is thus to assess properly creativity to support and guide its development and to contribute to the identification of children with special needs (e.g., gifted children with school difficulties).

The goal of this article is not to review exhaustively the large number of assessment methods - which essentially present all the same limits - but rather to provide an overview of the field and the different ways to measure the creative potential that can be used for educational purposes. First, we propose a general presentation of the field of creativity and the context in which different approaches to the concept emerged. Second, we describe the main methods of assessment available, with emphasis on the most popular techniques, their advantages and limits. Third, we present EPoC (Evaluation of Potential for Creativity [1]) a new multifaceted, domain-specific, modular test battery that allows evaluators to capture the multidimensionality of the creative potential to derive profiles of potential for creativity. Finally, we contextualize creativity assessment methods by addressing their use and misuse in the classroom and educational settings.

*Address correspondence to this author at the Child Study Center, Yale University, 230 South Frontage Rd., New Haven, CT 06520-7900, USA; Tel: (+1) 203-785-4239; Fax: (+1) 203-785-3002;

E-mail: baptiste.barbot@yale.edu

\section{HISTORICAL PERSPECTIVE ON CREATIVITY ASSESSMENT}

The field of creativity has dramatically expanded since the second half of the last century. In fact, the term "creativity" itself was not systematically employed before the 50's although a clear interest was apparent in a few - but still influential - works on the topic, including philosophical essays (e.g., Bergson, James), introspective descriptions of the concepts of scientific discovery and invention by recognized scientists (e.g., Poincaré, Einstein), conceptual models of the creative process [2], and the first empirical studies in the 40's [3, 4]. In fact, until the 50's, the study of creativity was, thus far, essentially related to the study of gifted or talented individuals, and therefore mainly interpreted as an exceptional process. Consequently, assessment of creativity was not a primary concern at the time because creativity was recognizable by the extraordinary creative outcomes / achievements of individuals. It is, however, worth noting that Binet's pioneer test battery for intelligence assessment in children [5, 6] included some items on "creative imagination" - not items of creative potential per se - that were progressively dropped from the test battery along with the "purification" of the concept of intelligence.

Since Guilford's [7] presidential address to the American Psychological Association, and other pioneering work of the time, creativity has been viewed as a psychological dimension that is widely distributed in the general population, which can be developed and measured. This new approach to the concept marks the starting point for modern interest in creativity and corresponds to an increasing focus on "everyday" creativity, "mini-c" creativity or "psychological" creativity - as opposed to historical creativity, eminent creativity, big-C creativity or genius [8-10]. From this time, and more clearly from the 60's, the field of creativity has seen a progressive increase of the description and definition of the concept, development of measures and assessment techniques, including major works that strongly influenced the field nowadays [11-13]. However, in the 90's, 
the creativity research literature increased exponentially with the appearance of new scientific journals, international conferences and book series on the topic, which coincided on the other hand, with significant progress in psychometric science.

Due to the multiplicity of the conceptual approaches of creativity used at that time, the field of creativity assessment was viewed as experiencing a "mid-life crisis" [14] with a problematic proliferation of assessment techniques showing lack of definition and limited educational applications [14]. Most of these numerous techniques and new assessment tools have also been criticized for their weak psychometric properties or lack of up-to date norms to situate individual performance in developmental, gendered and culturalrelevant groups of comparison [15]. These major issues in creativity assessment reduced dramatically the number of efficient techniques available. Again, it is likely that imprecision surrounding the definition of creativity was the source of most of the difficulty encountered in assessment and the proliferation of assessment tools.

Indeed, defining creativity is a research topic per se [16]. As an illustration, Treffinger [17] reviewed and presented more than 100 different definitions from the literature and there are at least as many techniques to assess it [15] probably because numerous scientists dealt with this conceptual issue by proposing both a definition of creativity and a method for its assessment. However, assuming that there is not a certain consensus, or a least some core elements to define creativity would be incorrect. Indeed, a usual way to define creativity is the ability to produce something which is both new/original and task/domain appropriate [18-22].

Whatever the definition of creativity used, post Guilford, and still currently, important research efforts tried to identify the psychological factors that best predict creative outcomes and many assessment techniques for creative potential have used these relevant factors surrounding creative potential as a means to measure creativity. In other words, measures of "components" involved in creativity — in particular, divergent thinking measures, that we will review in the next section - have, been interpreted, wrongly, as "pure measures" of "general" creative potential.

It is today accepted that no single ability or trait is the key to creativity. Indeed, creativity involves a combination of cognitive (information processing), conative (personality traits, motivational aspects), and emotional factors (affective state, trait) that are interacting dynamically with the environment (which stimulates or inhibits the expression of creative potential; see Besançon and Lubart [23]) resulting in the uniqueness of the creative process and product. It is hypothesized that, as these factors are present to varying degrees in each individual, both ordinary and exceptional levels of creativity can be explained by a specific combination of these factors (exceptional levels would result in an optimal combination of these factors, which is obviously extremely rarely found in the general population). Furthermore, it is accepted that the ability to produce creative work is partly domain-specific because the nature of creativity varies with the field, and could even vary as a function of the task within a domain [24] or the constraints within the task [25]. Consequently, the concept of creativity has evolved toward a "multivariate" framework, in which creativity is viewed as a multi-faceted and domain-specific ability, which can be developed and can be assessed properly by assessment tools tapping into the multidimensionality of this ability [1]. These many faces of creativity that no one single measurement instrument can capture resulted in a new modern myth on creativity, that there really aren't any good tests of creativity [26].

\section{DIFFERENT MEASURES, DIFFERENT GOALS, SAME ISSUES}

As suggested above, creativity assessment developed along with the evolution of the concept of creativity, and along with the questions that researchers addressed when developing their tools (questions that were representative of their time). As the field has been expanding, many techniques have been developed. A thorough review of these tools is not the purpose of the present article; for this specific end, there are many reviews and discussions on the numerous instruments, procedures, and methods that have been used to assess creative processes, products, or persons, in the literature [14, 15, 26-37]. For example, Petrosko's early review [38] already mentioned hundreds of creativity tests. Haensly and Torrance [29] identified over 200 instruments focusing only on verbal, figural, or "general" creative abilities. Fishkin and Johnson's review [28] compared strengths and weaknesses of numerous methods used to assess children's creativity. Later, a useful monograph on creativity assessment for educators, published by the National Center on the Gifted and Talented [15] reviewed thoroughly over 70 creative assessment techniques, selected from a list of over a hundred. In addition to this "general" literature on creativity assessment, there are also multiple reviews on techniques to assess creativity in specific domains of expression such as music [39-43].

Taken as a whole, instruments for creativity measurement have been categorized in different ways: type of instrument, "component" measured, and question addressed by the tools. Above all, Houtz and Krug [14] distinguished measurement, assessment and evaluation tools, which then can be divided by type: tests, self-report inventories, personality/preference inventories, and environmental indexes. As for the "component" measured by creativity assessment tools, Fishkin and Johnson [28] grouped the tools in categories representing the four P's dimension of creativity [44]: measures of process, personality, product and press (i.e. environment), whereas Treffinger et al. [15] differentiated measures according to their focus on the ability to generate ideas as opposed to the ability to dig deeper into ideas, listen to one's "inner voice", the openness and courage to explore ideas, or personal creativity characteristics.

Last but not least, instruments for creativity assessment can be categorized by the question they address (these questions can be mapped into different conceptions of creativity that can be situated historically). We suggest that, to date, instruments for measuring creativity can be grouped roughly into three main questions: Achievement measures would address the question "Is this student creative?" (interpretation of creativity as exclusively related to

\footnotetext{
${ }^{\mathrm{l}} \mathrm{http}: / /$ www.creativelearning.com/images/stories/freePDFs/AssessCreatRep
} ort.pdf 
giftedness or talent), whereas the componential ("unitary" measurement) approach mostly addressed the question "How creative is this student?". A recent focus on "style" leads us to ask a related question: "How is this student creative?" [45, 46]. Indeed, this question lends itself to the assumption that all students have a creative potential which takes different forms that can be identified and nurtured. The next section presents examples of the two previous traditions of measurement, whereas the last focuses on the more recent approach of measuring creative potential as a style.

\section{“Is this Student Creative?"(Creativity as a Status)}

When asking this question, the implicit conception of creativity refers to an exceptional process that is rarely observed in the general population; a process which is thus either present or absent. Measures addressing precisely this question therefore focus on the creative outcomes that one may or may not demonstrate. For instance, indicators of eminence (e.g., number of patents, scientific articles or musical compositions) have been used for a long time as a means to estimate individual's creativity [47]. Biographical inventories (e.g., Biographical Inventory for Students [48]) and achievement questionnaires (e.g., Creative Achievement Questionnaire [49]) are also good examples of this category. Typically, these self-report measures focus on past accomplishments in creative domains. The main assumption underlying the measurement of creative achievement is that, if one has already demonstrated creative outcomes, the probability to demonstrate other creative outcomes in the future is high (e.g., see Hocevar and Bachelor [30]) which is indeed tenable empirically (as demonstrated by Carlson et al. [49]). This type of approach is thus extremely limited when it comes to assess creativity in school settings, because it is rare to find creative achievement per se at the school age level (e.g., a published book or novel or released musical composition). Clearly, these measures are more adapted for adults who already demonstrated valuable creative outcomes, showed identifiable creative accomplishment, talents, expertise or special training in one or several creative domains.

\section{"How (How Much) Creative is this Student?" (Creativity as a Level)}

The answer raised by this question suggests a unitary conception of creativity - i.e. creativity is viewed as a continuous and unidimensional construct - with the implicit idea that creativity is present in each individual to various degrees. Since Guilford [7], this approach to creativity has been prevalent. As mentioned previously, many assessment techniques in this approach have in fact measured isolated components of creativity. The assumption behind this approach is that, by measuring a component of creative potential, one can have a good estimation of creative potential without distinction of the component, type of task, or domain of creative expression. Component measurements are thus, too often, interpreted as "pure measures" of general creative potential (if such a general potential exists). In addition to this difficulty, there are many candidate factors that could serve as indicators of creative potential because, to date, the characteristics presumed to indicate creativity may exceed 300 [26]. These factors are of different nature: cognitive, conative, or environmental. Product-based assessment is also commonly used to answer the question "How creative is this student?". These different paths to derive "levels" of creativity are described below.

\section{Measuring Cognitive Aspects}

Cognitive factors involved in creativity refer to basic processes of thought that lead to creative production, which include identifying, defining and redefining the problem, selective encoding (i.e., the ability to input environmental information related to a problem), divergent thinking, evaluation of ideas, associative thinking, and flexibility (see Lubart et al. [16]). However, a common definition of creativity from the cognitive approach makes reference to divergent thinking only [50]. Divergent thinking tests such as the Torrance Tests of Creative Thinking [12] or the Wallach and Kogan tests [13] are standardized tasks which evaluate the capacity of the individual to generate many ideas from a simple starting point, in a limited amount of time. This starting point can be, for example, a hypothetical situation (e.g., proposing many answer to the question "What would happen if strings were attached to the clouds?"), a graphic stimulus (e.g. supplement as many incomplete circles as possible by proposing original drawings using the graphic stimulus) or an object (e.g., propose various solutions for the improvement of a toy). Quantitative indicators reveal individual differences in the divergent thinking production generated in response to the stimuli during the allotted time. The number of ideas (ideational fluency) corresponds to the number of given answers, the variety of ideas (ideational flexibility) corresponds to the number of unique categories in which individual ideas can be ranked, and originality refers to the relative infrequency of each proposed idea in comparison to a population of reference. According to Guilford [7], divergent thinking is essential for creativity. It allows generating numerous ideas, enables the individual to consider alternative pathways of research, thus increasing the probability of finding an original and adapted idea [1].

Other measures of cognitive abilities involved in creativity include measures of problem-solving such as the Purdue Elementary Problem Solving Inventory [51] which consists of tasks for sub-process aspects of creative problem solving (e.g., problem identification, problem definition, generating questions and guessing causes, clarifying the goal, analyzing details, or verifying solutions). The popular Mednick and Mednick' Remote Associates Test [52] is also a measure frequently used to capture associative thinking (creative ideas come about when elements which are not usually associated together are, in fact, made to relate in a new and appropriate way).

Many of these early measures (divergent thinking tests and other creative cognition tests) have been criticized for sampling only a narrow range of creative behaviors [53], even though they have also shown evidence of long-term predictive validity with measures of adult productivity [54, 55]. Unfortunately, many limits of these tools can be noted, in particular the use of old standards in psychological assessments [28]. More importantly, nowadays these instruments rarely provide adequate norms (i.e., updated and appropriate benchmarks for relevant criteria such as age, gender, and culture), and the implicit approach of creative 
potential underlying the development of these tools appears also obsolete.

\section{Measuring Conative Aspects}

Conative factors refer to preferred ways of behaving (personality and motivationally related). Conceptually, it is conceived that these factors facilitate (or inhibit) the effective use of cognitive factors involved in the creative process [56]. Creative personality measures have been reviewed extensively [45], suggesting a wide diversity of measures. Many personality traits have indeed significant relationships with creativity [16]: the "core" factors include perseverance (the tendency to overcome obstacles, surrounding problem solving and the process of accepting change), tolerance for ambiguity (tendency to consider solutions, as ambiguous as they are), openness to new experiences (the tendency to be open to the unknown); individualism (characterized by a search for independence, allowing the emergence of unconventional solutions); risktaking (proposing a new idea contains a risk that this idea be rejected); psychoticism (involving a tendency to develop distant or eccentric associations, if mastered, can lead to original ideas). Also, Selby et al. [45] pointed the importance of many other factors such as self-acceptance, dominance, self-confidence, willingness to admit unusual and unconventional self-views, non conformity. Many self- or informant- rating scales and inventories have been proposed in this category of measure to capture these various aspects of creative personality. They include tools such as, the Barron-Welsh Art Scale [57], or the Creative Perception Inventory $[58,59]$ in which individuals are asked to autoevaluate themselves and check personality traits relative to creative personality or characteristics that typify their behavior. We can also mention the well-known Gough's Adjective Checklist [60] that includes a creative personality scale which captures more broadly the creative personality attributes.

The motivational dimension involved in creativity is also a factor often targeted to capture aspects of creative potential. Theoretically, novelty-induced motivation influences the nature and strength of individuals' engagement in creative activity. When motivation is assessed in relation to creative production, intrinsic motivation (task oriented motivation) predicts a greater degree of creativity (assessed by measures of creative products) than extrinsic motivation (reward oriented motivation). For instance, as evidenced by Amabile [18], poems generated for intrinsic reasons are considered significantly more creative than when they are made for extrinsic reasons. Moneta and Siu [61] showed that intrinsic motivation in school (measured using the Work Preference Inventory; [62]) predicted greater creativity in a writing task of story composition. Other measures include, for example, the Torrance Creative Motivation Scale [63].

One of the main psychometric difficulties with these scales is the unverifiable, subjective nature of people's reported creative accomplishments or self-description and the potential for biases, such as halo effects in self-reports [24] or social desirability [1]. Furthermore, for the cognitive components we noted, the conative approach to the measurement of creative potential captures only isolated aspects of creativity with the assumption that the particular component is an equivalent (or good enough predictor) of creative achievement; creativity being viewed as a broad ability without distinction of the particular domain or work involved within the domain. As they reflect "general tendencies", it is indeed possible that self-report inventories lead to a more general-oriented conception of creativity [64]. However, it is also possible that the apparent "generalized" creativity captured through these instruments (observed by correlations between these measures) reflects common biases (i.e., halo effects and social desirability) that underlie the answers in these instruments.

\section{Measuring Environmental Aspects}

Several environmental factors have been found to contribute to creative potential. These include factors such as parental practices [65], school environment [66], and even birth order [16]. The effects of teaching methods have also to be considered. For example, alternative pedagogies (e.g., Freinet or Montessori schools) have been found to be more conducive to children's creative development in primary education than traditional approaches [23]. Because, important environmental factors have been identified and recognized as contributors to an individual's creativity, the instruments identifying the presence or absence of these factors in the child's environment help estimate the extent to which children are likely to have a strong creative potential. To this end, there are quite a number of observational and/or rating scales for assessing environmental characteristics, classroom atmosphere and learning environments [14] favorable to individual creativity. For example, measures of school environment favorable to creativity include, the Classroom Activities Questionnaire [67]. However, the ability of these instruments to represent creative potential may vary as a function of individuals' "absorption rate" [39] of the environmental factors, which however, might be difficult to capture.

\section{Product-Based Assessment}

A common way to assess creative potential involves the achievement of a creative product based on initial elements or constraints [68]. These include producing a story, a drawing, a musical composition, based on predetermined criteria (e.g. integrate various heterogeneous elements in a drawing, inventing a story based on a title). This type of standardized tasks thus simulates partly real creative work and involves the ability of putting together several ideas; synthesizing them, to achieve a unique, original production integrating the imposed constraints or elements. Along with the involvement of this convergent-integrative mode of thinking (which we will describe further) in this type of task, many other aspects of the creative potential may be involved (cognitive, conative, and environmental aspects) and the resulting creative products become comparable with each other due to the standardized nature of the tasks. Typically, these products are then evaluated by experts of the domain using the Consensual Assessment Technique [69]. This technique is built upon the caveat that judgments about creativity imply a social consensus because there is no absolute norm for assessing the creativity of production (productions are evaluated relatively, each one against the others). Technically, domain-appropriate judges are asked to score independently a series of productions resulting from the same task, using a Likert scale (e.g. from "1- not creative 
at all", to "7-highly creative"). A statistical consensus is then estimated to ensure inter-rater agreement. The idea behind this procedure is that, if every expert agrees to "classify" the same creative products in the same order for their level of creativity (resulting in high inter-rater agreement), it is possible to conclude that raters have identified the same quality (that is, creativity). When the consensus is reached (as indicated by a statistical criteria), the scores given by each judge to each production can be averaged to derive a composite score of creativity. In other words, the accumulation and convergence of expertise by multiple informants for the same "subjective" quality results in a consensual measure. A computerized interface, the "Consensual Assessment Technique - interface" (CAT-i) ${ }^{2}$ allows the implementation of such product-based assessment via the Internet, in order to manage creative product and raters who are geographically distant, in a straightforward and methodologically-suitable manner (i.e. following recognized guidelines for consensual assessment such as Hennessey's [70]).

Even though product-based assessment is a more integrated approach to creative potential (involving presumably many components of the creative potential), this method for creativity assessment is insufficient - solely - to provide an overall estimate of individual's creative potential. Indeed research evidence has shown only limited overlaps between product-based measures in diverse domains [71]. Accordingly, performance-based evaluations provide results favoring a domain-specific view of creative behaviors [24,64].

\section{Looking Back: The State of the Art in Creative Potential Assessment}

The large number of assessment techniques mentioned above reflects two major issues on creativity assessment. First, creativity is a multifaceted, domain-specific construct, so instruments to measure creativity may vary as a function of the domain-component aimed at being measured. Second, there are correspondingly many definitions of the concept, but still no clear definition of creativity on which to base instrument development [14]. As a consequence, most of what we know today about creativity is derived from assessment tools that are based, themselves, on pre-defined conceptions of creativity. More importantly, there is to date only little evidence as to the stability, factor complexity, or predictive validity of most measures and methods, leading many authors to lament the failure of existing measurement methods [14,29]. Finally, we noted thorough the above review the lack of up-to-date, developmentally, gendered and culturally appropriate norms for most instruments and the tendency of "unidimensional" measures of creative potential (such as divergent thinking tests) being interpreted as the equivalent of all creative potential (which is actually more a question of misuse of the test scores, rather than a deficiency of the instruments per se).

Thus, unlike other domains of human cognition such as intelligence, in which "mainstream" instruments exist, with relatively few alternatives, a comparatively narrow research topic - that is, creativity - has generated an important amount of assessment techniques with difficulties to find a

${ }^{2}$ www.cat-i.org consensual approach. To address these major issues on creativity assessment, a few recommendations have emerged from the literature. First, the failure to achieve commonly agreed upon definitions of creativity, creative thinking, or creative problem solving should not be an excuse to abandon efforts to invent new measures or to improve the predictive validity of existing measures [14]. For example, Michael and Wright [33] recommended that theoretically-oriented psychologists combine their efforts with those of psychometricians to formulate new conceptual frameworks for creativity that they can empirically test. Houtz and Krug [14] also proposed some principles for further development of creativity assessment techniques. These principles included the need to multiply the assessment approaches to yield a more complete picture of an individual's potential for creativity, as recommended by many other authors $[27,28$, 31, 72].

\section{New Perspective on Creativity Assessment: "How (and where) is this Student Creative?" (Creativity as a Style)}

Research informs us that individuals vary, not only in relation to level of creativity, but in relation to style of creativity as well [73] and that effective assessment of creativity involves a profile of characteristics [14, 15, 26, 74]. Thus, an increasingly important question to address by creativity assessment tools is "How is this student creative?"[46]. This question, built upon the previous tradition of creativity assessment, goes beyond the notion of "status", "degree", or "level" of creative potential, as emphasized in the "componential-unitary" measurement approach, and even more as in the "eminence" approach, which respectively put emphasis either on a dichotomous or on a unidimensional approach to creativity. Rather, it underlies the "form" that creative potential can take and it implicitly includes both questions "Where is this student creative?" (creativity as a domain specific ability) and "How the creative potential of this student is expressed across various dimensions?" (multifaceted concept of creative potential). In other words, this new perspective on creativity assessment emphasize the importance to take into account the multidimensionality and domain specificity of the construct of creativity, when assessing creative potential in children. Only a few authors have addressed the domainspecificity issue in creativity assessment [24, 72] which however has implications in the field of education. Indeed, some periods of development may be best for promoting general creative achievement, and during other periods it may be best to focus on specific creative activities [24]. As such, it appears important to extend the former tradition of assessment, by developing instruments that measure creative potential in diverse domains of creative expression "developmentally relevant" and through diverse modes of thinking in order to capture the range of creative abilities. Until the development of EPoC [1] that we present further in the next section, the 2000's have seen relatively few - and perhaps no - techniques for the assessment of creativity following these recommendations.

\section{EPOC: A NEW INSTRUMENT}

To overcome the limitations of the various methods mentioned previously, we developed the Evaluation of Potential for Creativity (EPoC [1]) which is an up-to-date 
measurement tool for children in elementary and middleschool students $\left(\mathrm{K}-6^{\text {th }}\right)$. EPoC is indeed a synthesis and extension of several traditions of measurement, which is based on a current theoretical framework envisioning creativity as a multifaceted, domain-specific construct that involves many components. Based on the multivariate approach of creativity, the main tenets guiding EPoC development suggest that, first, it is possible to categorise the numerous micro-processes involved in creative potential into two main sets, called divergent-exploratory processes, and convergent-integrative processes [1]. Second, as creativity is partly (if not primarily) domain specific, it is important that measures of creative potential take into account the domain of creative expression [24, 72, 78]. Consequently, EPOC measures both sets of micro-process (divergent-exploratory and convergent-integrative, as opposed to previous measurement tools that typically measure a single component), in diverse domains of expression, whereas the previous approaches of creativity measurement had rather a generalist approach (tending to generalise the observed results to any domain of creative expression).

In EPoC, divergent-exploratory and convergentintegrated modes are hypothesized to occur in cycles during the creative process, which take different forms (frequency and length of the cycles) as a function of the creative task and individual preferences (i.e. creative style), influencing the quality of the resulting production. The divergentexploratory mode of thinking refers to the process of expanding the range of solutions in creative problem solving and includes factors such as flexibility, divergent thinking, selective encoding, which are supported by personality traits, such as openness to experiences and intrinsic task-oriented motivation. Convergent-integrative thinking refers to the activity of combining elements in new ways, which is the second fundamental aspect of the creative work. This ability involves micro-process such as associative thinking, selective comparison and combination allowing a synthesis of various heterogeneous elements to converge into a unique, original production. Relevant supporting conative factors of convergent-integrative thinking include, for example, tolerance for ambiguity, perseverance, risk taking, and achievement motivation.

EPoC includes two alternative forms (Form A and Form B) so that users can assess the progress made by children in pre-test post-test study design (e.g. to assess the efficiency of creativity-based training and interventions programs), or simply assess change overtime to monitor the development of creative potential. Each of EPoC's forms is composed of eight subtests covering, to date, two developmentally appropriate domains of expression (verbal and graphic) and addressing the two modes of thinking described above. EPoC tasks are designed to arouse creative potential through these two domains and two modes of thinking by putting children in situations of creation. In divergent-exploratorytype tasks, children are asked to generate many ideas in response to a single stimulus or problem (involving processbased assessment approach focusing on the quantity of the production), whereas the convergent-integrative-type task consists of producing an integrated composition which is more elaborated and finalized (involving a product-based assessment approach focusing on the quality of the production). For example, a task of Divergent-Exploratory thinking in the Verbal domain consists of proposing as many story endings to a single story beginning as possible in 10 minutes. Each answer must be original and different from the previous answer. In contrast, a task of ConvergentIntegrative thinking in the Graphic domain consists of generating in 15 minutes a single, original and integrated drawing which combines a set of heterogeneous elements presented on a photo (including objects such as a suitcase, a fruit, a candle). Resulting drawings are then rated using 7 points Likert scales. These diverse tasks sample suitably important facets of the creative potential and allow, based on EPoC's underlying theoretical model and factorial structure, to compute four scores: Divergent-Exploratory thinking in the Graphic domain (DG), Divergent-Exploratory thinking in the Verbal domain (DV), Convergent-Integrative thinking in the Graphic domain (IG), and Convergent-Integrative thinking in the Verbal domain (IV). These test scores are reliable with inter-subtest correlations ranging from .60 to .78 (equivalent to Cronbach Alpha ranging from .75 to .88) depending on the dimension. Results are interpreted in terms of efficiency and creative potential style, based on EPoC's profile. These styles emphasize individual "preferences", such as the likelihood to perform well in a particular domain (e.g., high score in DG and IG, suggesting a "preference" for the graphic domain across processes) or a specific mode of thought (e.g., high scores of IG and IV, suggesting a "preference" for the Convergent-Integrative thinking mode across domains). These EPoC profiles thus provide useful insights to tailored creativity-based educational programs aiming to guide the development of creativity appropriately, or in a diagnostic perspective (e.g. for the detection of children with high creative potential on the four EPoC indices).

EPoC was initially developed and validated in a sample of French students and is presently available in this country (EPOC [1]). Internal validity has been informed by confirmatory factor analysis proving an acceptable adjustment of the data to the theoretical model for both form $A$ and form B. External validity also proved to be satisfactory with an independence of EPoC scores with a measure of IQ, a moderate correlation between EPoC scores and personality-relevant dimensions such as openness to new experience, and moderate to high correlations between EPoC scores and classic subtest of divergent thinking derived form the Torrance test, indicating both convergent and divergent validity. Developmentally-appropriate norms are available to situate the performance of the assessed child in comparison to his/her age-group and an original internet-based training system (based on the CAT-i platform) ${ }^{3}$ is offered to enhance rater accuracy in scoring creative productions resulting from EPoC tasks. Diverse developments of EPoC are currently in progress: 1) it is translated and adapted in several countries (including the development of local norms), 2) norms for adolescents (middle to high school level) are under preparation, 3) extension of the test battery for new domains of creative expression are under development (including social, scientific, and musical domains), and 4) a computerized version is envisioned.

\footnotetext{
${ }^{3} \mathrm{http}: / /$ www.cat-i.fr/hogrefe/
} 
To summarize, EPoC is a modular, domain-specific tool, which presently includes verbal and graphic subtests that measure the two key modes of creative thinking - divergentexploratory thinking and convergent-integrative thinking-in elementary and middle-school students. As such, EPoC is the first tool in the history of creativity assessment that combines an approach by domain of creative expression and by mode of thinking, in order to capture the diversity of creative abilities of children. This up-to-date approach thus offers a broader vision of creative potential in children and proves useful as a monitoring tool to guide the development of creativity.

\section{PERSPECTIVE ON THE APPLICATION OF CREATI- VITY MEASUREMENT IN CLASSROOM SETTINGS}

"We frequently hear the charge that under present day mass-education methods, the development of creative personality is seriously discouraged. The child is under pressure to conform for the sake of economy and for the sake of satisfying prescribed standards" [7].

Over six decades after Guilford [7], this statement makes still great sense, and while creativity and innovation are features of human behaviors more and more valued in modern societies, few policy efforts and educational practices are concentrated into the development of creativity in classroom context. Indeed, specialized instruction for teachers in creativity and in creativity assessments are often recommended topics for teacher preparation programs but are rarely realized [14]. Even though teachers declare liking "creative students", research shows that creative characteristics appear to be unappealing to the same teachers [75].

However, Guilford himself emphasized the need to encourage the development of creativity [7]. "This development might be in the nature of actual strengthening of the functions involved or it might mean the better utilization of what resources the individual possesses, or both" (p. 448). Broadly, the construct of creativity has a great deal to offer educational psychology [34]. Many empirical studies on the development of creativity and creativity-relevant attributes established that an individual's creative productivity can be improved through instruction $[15,76]$, suggesting that training is possible, at least to some degree.

In echo with the "unitary" assessment issue, training has for a large part focused on isolated components of creative potential (such as divergent thinking) with the hypothesis that the stimulation of a specific process in a specific domain would result in global support of creative potential. Unfortunately, some research results show evidence that divergent training shows only limited transferability to other domains [77]. In other words, it appears that training programs to foster "global" creativity development are inappropriate. Given this, the most effective training programs will be those tailored to enhance creativity in a specific domain, and even better in a specific task [78]. Of course, educators aiming to encourage creative potential should be careful not to use or develop training programs that could be qualified of "training for the test" by focusing only on narrow aspect of creative potential that are captured by most creativity tests. Indeed, training programs that focus on one or a small number of abilities are bound to yield limited effects on the development of creativity [24]. Correspondingly, Tan et al. [79] encourage integrative instructional activities (in the domain of creative writing), that lead children to "think like writers", rather than promoting artificial activities such as the practice of "brainstorming" ideas in a whole group session, as a basis to creative writing exercises. Indeed this particular approach can lead students to conform their ideas to the themes and elements emerging from the collective brainstorming exercise [80]. This illustration emphasizes that it is important to foster multiple components of creative potential in a way that is relevant to the domain and the specific task within the domain (e.g. writing poems). To be even more effective, creativity training could be tailored to each child's needs by determining which component of creative potential could be improved in a specific domain. Therefore, multidimensional assessments of creative potential such as EPoC are relevant to identify children's specific needs as a means to guide their creativity development.

\section{CONCLUSIONS}

An important issue for both creativity research and practical applications is to assess creativity to support and guide creative development. However, existing creativity assessment tools are limited, especially for their lack of up-to date norms and theoretical framework. We presented a new instrument that allows creative potential to be measured (Evaluation of Potential Creativity, EPoC [1]), based on solid theoretical and research-based evidence for creativity assessment. This instrument allows researchers, educators, and teachers to capture more broadly the creative potential of children, so that it can be better described and nurtured.

\section{ACKNOWLEDGEMENTS}

The authors thank Gabrielle Santa-Donato and Jeffrey Plante for their editorial assistance and their help in the preparation of the manuscript.

\section{CONFLICT OF INTEREST}

None declared.

\section{REFERENCES}

[1] Lubart TI, Besançon M, Barbot B. Evaluation du Potentiel Créatif (EPoC). Paris, France: Editions Hogrefe 2011.

[2] Wallas G. The Art of Thought. New York: Harcourt Brace 1926.

[3] Hadamard J. The psychology of invention in the mathematical field. Princeton, NJ: Princeton University Press 1945.

[4] Patrick C. Creative thought in artists. J Psychol 1937(4): 35-73.

[5] Binet A. New methods for the diagnosis of the intellectual level of subnormals. L'Annee Psychologique 1905; 12: 191-244.

[6] Binet A, Simon T. Le development de l'intelligence chez les enfants. L'Annee Psychologique 1908; 14: 1-94.

[7] Guilford JP. Creativity. Am Psychol 1950; 5: 444-54.

[8] Richards R. Everyday Creativity, Eminent Creativity, and Health. Creat Res J 1990; 3: 300-26.

[9] Gardner H. Creating Minds : An Anatomy of Creativity Seen Through the Lives of Freud, Einstein, Picasso, Stravinsky, Eliot, Graham and Ghandi. [S.1.]: Basic Books 1994.

[10] Boden M. The creative mind. New York: Basic Books 1992.

[11] Guilford JP. The nature of human intelligence. New York: McGraw-Hill, 1967.

[12] Torrance EP. The Torrance Tests of Creative Thinking-NormsTechnical Manual Research Edition-Verbal Tests, Forms A and BFigural Tests, Forms A and B. 1966. 
[13] Wallach M, Kogan N. Modes of thinking in young children. New York: Holt, Rinehart \& Winston 1965.

[14] Houtz J, Krug D. Assessment of creativity: Resolving a mid-life crisis. Educ Psychol Rev 1995; 7(3): 269-300.

[15] Treffinger DJ, Young GC, Selby EC, Shepardson CA. Assessing creativity: A Guide for educators. National Research Center on the Gifted and Talented 2002.

[16] Lubart TI, Mouchiroud C, Tordjman S, Zenasni F. Psychologie de la créativité. Paris, France: Armand Colin 2003.

[17] Treffinger DJ. Creativity, creative thinking, and critical thinking: In search of definitions. Sarasota, FL: Center for Creative Learning 1996.

[18] Amabile TM. Creativity in context. Boulder, CO: Westview 1996.

[19] Barron F. Putting creativity to work. In: Sternberg RJ, Ed. The nature of creativity: Contemporary psychological perspectives Cambridge, UK: Cambridge University Press 1988; pp. 76-98.

[20] MacKinnon D. The nature and nurture of creative talent. Am Psychol 1962; 17: 484-95.

[21] Ochse R. Before the gates of excellence: The determinants of creative genius. New York: Cambridge University Press 1990.

[22] Sternberg RJ, Lubart TI. Defying the crowd: Cultivating creativity in a culture of conformity. New York: Free Press 1995.

[23] Besançon M, Lubart TI. Differences in the development of creative competencies in children schooled in diverse learning environments. Learn Individ Differ 2008; 18(4): 381-9.

[24] Lubart TI, Guignard J. The generality-specificity of creativity: A multivariate approach. In: Sternberg RJ, Grigorenko EL, Singer L, Eds. Creativity: From potential to realization Washington, DC: American Psychological Association 2004; pp. 43-56.

[25] Treinen E, Barbot B. Effect of stimuli in figural divergent thinking abilities among adolescent. Conference of the International Center for Innovation in Education (ICIE). July 2-4, 2008; Paris, France 2008.

[26] Treffinger DJ. Myth 5: Creativity is too difficult to measure. Gifted Child Quarterly 2009; 53: 245-7.

[27] Feldhusen JF, Goh BE. Assessing and accessing creativity: An integrative review of theory, research, and development. Creat Res J 1995; 8: 231-47.

[28] Fishkin AS, Johnson AS. Who is creative? Identifying children's creative abilities. Roeper Rev 1998; 21(1): 40-6.

[29] Haensly PA, Torrance EP. Assessment of creativity in children and adolescents. In: Reynolds CR, Kamphaus RW, Eds. Handbook of Psychological and Educational Assessment of Children: Intelligence and achievement New York: Guilford Press 1990; pp. 697-722.

[30] Hocevar D, Bachelor P. A taxonomy and critique of measurements used in the study of creativity. In: Glover JA, Ronning RR, Reynolds CR, Eds. Handbook of Creativity. New York: Plenum; 1989; pp. 53-75.

[31] Hunsaker SL, Callahan CM. Creativity and giftedness: Published instrument uses and abuses. Gifted Child Quarterly 1995; 39: 110-4.

[32] Kaufman JC, Plucker JA, Baer J. Essentials of creativity assessment. New York: Wiley 2008.

[33] Michael WB, Wright CR. Psychometric issues in the assessment of creativity. In: Glover JA, Ronning RR, Reynolds CR, Eds. Handbook of Creativity. New York: Plenum 1989; pp. 33-52.

[34] Plucker JA, Beghetto RA, Dow GT. Why isn't creativity more important to educational psychologists? Potentials, pitfalls, and future directions in creativity research. Educ Psychol 2004; 39: 83-96.

[35] Puccio G, Murdock MC editors. Creativity assessment: Readings and resources. Buffalo, NY: Creative Education Foundation 1999.

[36] Sternberg RJ, Lubart TI. Creativity: Its nature and assessment. School Psychol Int 1992; 13(3): 243-53.

[37] Treffinger DJ. Research on creativity assessment. In: Isaksen SG, Ed. Frontiers of creativity research: Beyond the basics Buffalo. NY: Bearly Limited 1987; pp. 103-19.

[38] Petrosko J. Measuring creativity in elementary school: The current state of the art. J Creat Behav 1978; 12: 109-19.

[39] Auh M. Assessing Creativity in Composing Music: ProductProcess-Person-Environment Approaches. Proceedings of the 2000 National Conference of the Australian Association for Research in Education. Sydney, Australia: UTS 2000.

[40] Hickey M. Creativity research in music, visual art, theatre, and dance. In: Colwell R, Richardson C, Eds. The new handbook of research on music teaching and learning. Auckland: Oxford University Press 2002; pp. 398-414.
[41] Mialaret JP. Explorations musicales instrumentales chez le jeune enfant (musical instrumental explorations in young child). Paris: PUF 1997.

[42] Richardson CP. Creativity research in music education: A review. Bulletin of the Council on Research in Music Education 1983; 74: $1-21$.

[43] Webster P. Research on creative thinking in music: the assessment literature. In: Colwell R, Ed. Handbook of research on music teaching and learning. New York: Macmillan Publishers 1992; pp. 266-79.

[44] MacKinnon DW. The study of creativity. In: MacKinnon DW, Ed. The creative person Berkeley, CA: Institute of personality Assessment Research, University of California 1961; pp. I-1 - 1-15.

[45] Selby EC, Shaw EJ, Houtz JC. The creative personality. Gifted Child Quarterly 2005; 49: 300-31.

[46] Treffinger DJ, Selby EC, Isaksen SG. Understanding individual problem solving style: A key to learning and applying creative problem solving. Learn Individ Differ 2008; 18: 390-401.

[47] Simonton DK. Thematic fame, melodic originality, and musical zeitgeist: A biographical and trans-historical content analysis. J Pers Soc Psychol 1980; 39: 972-83.

[48] Siegel L. A Biographical Inventory for Students: II. Validation of the Instrument. J Appl Psychol 1956; 40(2): 122-26.

[49] Carson SH, Peterson JB, Higgins DM. Reliability, validity, and factor structure of the Creative Achievement Questionnaire. Creat Res J 2005; 17: 37-50.

[50] Guilford JP. The nature of human intelligence. New York: McGraw-Hill 1967.

[51] Feldhusen JE, Houtz JC, Ringenbach S. Development of the Purdue Elementary Problem Solving Inventory Psychological Reports 1972; 31: 891-901.

[52] Mednick SA, Mednick MT. Examiner's manual: Remote Associates Test. Boston: Houghton Mifflin 1967.

[53] Borland JH. Planning and implementing programs for the gifted New York: Teachers College Press 1989.

[54] Milgram RM, Hong E. Creative thinking and creative performance in adolescents as predictors of creative attainments in adults: A follow-up study after 18 years. In: Subotnik RF, Arnold KD, Eds. Beyond Terman: Contemporary longitudinal studies of giftedness and talent. Norwood, NJ: Ablex 1994; pp. 212-28.

[55] Torrance EP, Salter HT. The Incubation Model of Teaching: Getting Beyond the Aha! Buffalo, NY: Bearly Limited 1990.

[56] Mumford MD, Gustafson SB. Creativity syndrome: Integration, application, and innovation. Am Psychol Assoc 1988; 1(103): 2743.

[57] Welsh GS, Barron F. Barron-Welsh art scale. Palo Alto, CA: Consulting Psychologists Press; 1963.

[58] Khatena J, Morse D. Khatena-Morse Multitalent Perception Inventory. Bensenville, IL: Scholastic Testing Service 1994.

[59] Khatena J, Torrance EP. Khatena-Torrance Creative Perception Inventory. Chicago, IL: Stoelting Company 1976.

[60] Gough HG. A creative personality scale for the adjective check list. J Pers Soc Psychol 1979; 37(8): 1398-405.

[61] Moneta GB, Siu CM. Trait intrinsic and extrinsic motivations, academic performance, and creativity in Hong Kong college students. J Coll Stud Dev 2002; 43: 664-83.

[62] Amabile TM, Hill KG, Hennessey BA, Tighe EM. The work preference inventory: Assessing intrinsic and extrinsic motivational orientations. J Pers Soc Psychol 1994; 66: 950-67.

[63] Torrance EP. Creative Motivation Scale. Bensenville, IL: Scholastic Testing Service; 1987.

[64] Plucker JA, Runco MA. The death of creativity measurement has been greatly exaggerated. Roeper Rev 1998; 21(1): 36-9.

[65] Lautrey J, Lubart TI. Créativité. In: Houdé O, Kayser D, Koenig O, Proust J, Rastier F, Eds. Vocabulaire des sciences cognitives neurosciences, psychologie, intelligence artificielle, linguistique et philosophie. Paris: PUF 1998; pp. 123-24.

[66] Clifford MM, Chou FC. Effect of payoff and task context on academic risk tasking. J Educ Psychol 1991; 83(4): 499-507.

[67] Cicchelli T. The Class Activities Questionnaire (CAQ). In: Keyser PJ, Sweetland RC, Eds. Test Critiques (Vol. 7) Kansas City, MO: Test Corporation of America 1989; pp. 110-18.

[68] Jellen HG. The TCT-DP (Test for Creative Thinking-Drawing Production): An instrument that can be applied to most age and ability groups. Creat Child Adult Q 1986; 11: 138-155. 
[69] Amabile TM. Social psychology of creativity: A consensual assesment technique. J Pers Soc Psychol 1982; 43: 997-1013.

[70] Hennessey BA. The consensual assessment technique: An examination of the relationship between ratings of product and process creativity. Creat Res J 1994; 7: 193-208.

[71] Lubart TI, Sternberg RJ. An investment approach to creativity: Theory and data. In: Smith SM, Ward TB, Finke RA, Eds. The creative cognition approach Cambridge, MA: MIT Press 1995; pp. 271-302.

[72] Han K, Marvin C. Multiple creatives? Investigating domainspecificity of creativity in young children. Gifted Child Quarterly 2002; 46: 98-109.

[73] Selby EC, Treffinger DJ, Isaksen SG, Lauer KJ. Defining and assessing problem solving style: Design and development of a new tool. J Creat Behav 2004; 38: 221-43.

[74] Isaksen SG, Puccio GJ, Treffinger DJ. An ecological approach to creativity research: profiling for creative problem solving. J Creat Behav 1993; 27(3): 149-70.
[75] Westby EL, Dawson VL. Creativity: Asset or burden in the classroom. Creat Res J 1995; 8: 1-10.

[76] Niu W, Sternberg RJ. Societal and school influences on student creativity: the case of China. Psychol Sch 2003; 40: 103-14.

[77] Baer J. The effects of task-specific divergent-thinking training. J Creat Behav 1996; 30: 183-7.

[78] Baer J. The case for domain specificity in creativity. Creat Res J 1998; 11: 173-7.

[79] Tan M, Barbot B, Randi J, Levenson C, Friedlaender LK, Grigorenko EL. Seeing, connecting, writing: Developing creativity and narrative writing in children. In: Grigorenko EL, Mambrino E, Preiss D, Eds. Handbook of writing: A mosaic of new perspectives. New York: Psychology Press; in press.

[80] Randi J, Jarvin L. An "A" for creativity: Assessing creativity in the classroom. Thinking Classroom 2006; 7(4): 26.

Received: June 16, 2011

Revised: July 6, 2011

Accepted: July 25, 2011

(C) Barbot et al.; Licensee Bentham Open.

This is an open access article licensed under the terms of the Creative Commons Attribution Non-Commercial License (http://creativecommons.org/licenses/by-nc/

$3.0 /$ ) which permits unrestricted, non-commercial use, distribution and reproduction in any medium, provided the work is properly cited. 